\title{
La aplicación de la política de "re-dimensionamiento" en la Universidad de Buenos Aires durante la última dictadura (1976-1983)
}

Guadalupe Seia

\section{RESUMEN}

En el presente artículo nos proponemos describir la política de "re-dimensionamiento" aplicada en la Universidad de Buenos Aires (UBA) durante la última dictadura en Argentina (1976-1983). Caracterizamos las principales modalidades utilizadas para "adecuar" el tamaño de las casas de altos estudios a los nuevos parámetros establecidos. Asimismo, analizamos los efectos que estas medidas tuvieron. Así, procuramos complejizar el conocimiento disponible sobre la política universitaria dictatorial en Argentina. Hemos utilizado una estrategia metodológica de triangulación de fuentes documentales oficiales de diversos tipos (estadísticas, memorias, discursos de autoridades, etcétera), de la prensa escrita y de testimonios orales recolectados en el marco de nuestra investigación.

Palabras clave: Universidad de Buenos Aires, política universitaria, dictadura, "re-dimensionamiento" de la matrícula estudiantil, Argentina. 


\section{A aplicação da política de "redimensionamento" na Universidad de Buenos Aires durante a última ditadura (1976-1983)}

\section{RESUMO}

No presente artigo nos propomos descrever a política de "redimensionamento" aplicada na Universidad de Buenos Aires (UBA) durante a última ditadura na Argentina (1976-1983). Caracterizamos as principais modalidades utilizadas para "adequar" o tamanho das casas de altos estudos aos novos parâmetros estabelecidos. Também, analisamos os efeitos que estas medidas tiveram. Assim, procuramos complexificar o conhecimento disponível sobre a política universitária ditatorial na Argentina. Utilizado uma estratégia metodológica de triangulação de fontes documentais oficiais de diversos tipos (estatísticas, memorias, discursos de autoridades, etc.) da imprensa escrita e de testemunhos orais coletados no marco da nossa pesquisa.

Palavras chave: Universidad de Buenos Aires, política universitária, ditadura, "redimensionamento" da matrícula estudantil, Argentina.

\section{The application of the "re-dimensioning" policy at the University of Buenos Aires during the last dictatorial period (1976-1983)}

\section{ABSTRACT}

In this article the authors intend to describe the policy of "re-dimensioning" applied in the University of Buenos Aires (UBA) during the last dictatorial period in Argentina (1976-1983). They characterize the main modalities used to "adapt" the size of the higher education institutions to the new established criteria. The authors also analyze the impact of these measures and aim to deepen the available knowledge about the dictatorial university policy in Argentina. They have used a methodological strategy of triangulation of official documentary sources belonging to diverse categories (statistics, reports, speeches by authorities, etc.), the written press and oral testimonies collected in the framework of their research.

Key words: University of Buenos Aires, university policy, dictatorship, "re-dimensioning" of student enrollment, Argentina.

Recepción: 13/01/17. Aprobación: 30/10/17. 


\section{Introducción}

El golpe de Estado del 24 de marzo de 1976 instaló en Argentina el denominado "Estado Terrorista" (Duhalde, 2013), caracterizado por la militarización del aparato del Estado y un alto contenido represivo que pretendió la aniquilación física de sus opositores y el amedrentamiento de la población a través del terror. El dispositivo represivo incluyó el secuestro, la tortura y la desaparición sistemática de personas así como el funcionamiento de centros clandestinos de detención. Continuando y profundizando lo iniciado años antes por el gobierno peronista, la universidad fue uno de los terrenos donde la represión paraestatal y estatal se asentó. Esto se hace observable en el hecho de su inmediata intervención y en que al finalizar la etapa, más del 20\% de los desaparecidos fueron estudiantes (Comisión Nacional sobre la Desaparación de Personas, CONADEP, 1984).

En el documento "Bases para la intervención de las fuerzas armadas en el proceso nacional" (1976) la Junta Militar definió como objetivo educacional el establecimiento de una política basada en la disciplina y contenidos nacionales y cristianos. Con ese marco, la Ley 21.276, "Prioridad para la normalización de las universidades nacionales" (1976) dispuso que el gobierno, la administración y la designación de autoridades de las universidades fueran ejercidos por el Ministerio de Cultura y Educación (MCE), que también quedaba facultado para resolver las situaciones "que afecten la paz, el orden interno de las universidades y su funcionamiento normal" (art. 4) no previstas en esta ley y para disponer del cese del personal docente y directivo (art. 10). Continuaba prohibida toda actividad de "adoctrinamiento, propaganda, proselitismo o agitación de carácter político o gremial" (art. 7).

En el diagnóstico de la dictadura, la raíz del problema estaba en la herencia del reformismo de 1918, que estimulaba a los jóvenes a politizarse y organizarse para formar parte del gobierno universitario. Como veremos en adelante, para "neutralizar el accionar subversivo y reconstruir la Nación", se procedió a restaurar "el orden imprescindible" para enseñar y aprender "en paz", mediante la acción de los delegados de las Fuerzas Armadas (FFAA) y la colaboración de "civiles con alto prestigio académico" (FFAA, 1979). También se separó de sus cargos a "totalitarios y corruptos" quienes habían "asaltado las cátedras teniendo como único mérito su militancia o simpatías marxistas" (FFAA, 1979), se desarrollaron algunos cambios institucionales y se continuaron medidas implementadas durante las gestiones anteriores. Entre las medidas dispuestas para el "reordenamiento de los claustros" se estableció la necesidad de "re-dimensionar" a las universidades que habían crecido desproporcionadamente en los años previos.

En este artículo nos proponemos describir y analizar las diversas modalidades de "re-dimensionamiento" propuestas y puestas en marcha durante la última dictadura en el caso de la Universidad de Buenos Aires (UBA), la casa de estudios más importante del sistema nacional en cuanto a su matrícula, su presupuesto y su centralidad política y cultural. De este modo, la investigación se ubica en el marco de una serie de trabajos recientes (Rodríguez y Soprano, 2009a y 2009b; Rodríguez, 2015a y 2015b; Águila, 2015; Algañaraz Soria, 2015; Orbe, 2015; Gil et al., 2015; Seia 2014 y 2015) que se han ocupado de reconstruir la aplicación de la política universitaria de la dictadura en diferentes casas de estudio (La Plata, Cuyo, Rosario, Comahue, Mar del Plata).

En este caso, como hemos sostenido, nos concentraremos en las medidas implementadas para lograr el "re-dimensionamiento" de la UBA. Buscaremos responder a una serie de interrogantes, tales como: ¿Por qué el "sobre-dimensionamiento" era parte del "problema universitario"? ¿Qué diagnósticos construyeron las nuevas autoridades educativas y universitarias sobre la situación de dicha institución? ¿Qué soluciones se buscaron a este aspecto del "problema universitario"? ¿Qué finalidad tenía la implementación de esas medidas? ¿Cómo y por quién fueron puestas en práctica en los claustros porteños? ¿Qué 
efectos tuvieron en la estructura de la mayor universidad nacional? Para hacerlo hemos trabajado con una estrategia metodológica de triangulación (Vasilachis de Gialdino, 1992) de diferentes fuentes oficiales (resoluciones rectorales, documentación de las FFAA y del MCE, prensa escrita, estadísticas oficiales, entre otros) y testimonios orales de estudiantes de esa época.

\section{Diagnosticando el "sobre-dimensionamiento"}

Hacia el final de la década de 1960, en Argentina, comenzaron a tomar estado público una serie de diagnósticos acerca de la situación universitaria nacional, coincidentes en que su principal problema consistía en el aumento masivo de la matrícula y la altísima tasa de deserción. Desde entonces, el llamado "problema universitario" adquirió una nueva dimensión. a la politización y radicalización de los estudiantes de la década de 1960 se sumaron los problemas propios de las estructuras universitarias. Para ese momento, el país tenía uno de los índices más altos de estudiantes universitarios en relación con su población (Mendonça, 2015; Califa y Seia, 2017). Cano (1985) ha descrito un crecimiento acelerado del alumnado universitario entre 1963 y 1975: de 182100 estudiantes se pasó a 300134 en 1970 y a 564293 en 1975. ${ }^{1}$

A mediados de la década de 1970 el denominado "problema universitario" continuaba incluyendo el considerable aumento de la matrícula estudiantil. Luego, en la gestión del ministro de Educación y Cultura, Oscar Ivanissevich (1974-1975), la cuestión de la matrícula se instaló como uno de los principales problemas por resolver en materia universitaria. Su sucesor, Pedro Arrighi (1975-1976), consideraba preocupante el crecimiento desmedido de las universidades nacionales y sus falencias en la distribución geográfica en tanto existía "macro-cefalismo" y facultades y carreras similares en instituciones cercanas entre sí. Sostenía que no había existido un planeamiento universitario coherente, generando el sobredimensionamiento del sistema y una duplicación de tareas. Se hacía necesario un plan de regionalización universitaria para reordenar el sistema (Arrighi, 1975). El caso de la UBA era particularmente relevante dado el protagonismo político, ideológico y cultural que esta casa de altos estudios tenía. Era la universidad nacional de mayor matrícula del país, en 1974 concentraba a 166215 estudiantes (Secretaría de Políticas Universitarias, 2015), y era centro de la radicalización política universitaria.

$\mathrm{Al}$ respecto, Pérez Lindo (1986) sostiene que para los sectores militares y de las clases dominantes (como así también para los grupos ideológicos de extrema derecha) la radicalización política de los universitarios tenía mucho que ver con el crecimiento desmedido de las universidades. Lo que para unos era un síntoma de "disfuncionalidad", para otros era el germen de la "subversión". Así, desde el golpe de estado de 1976, la reducción del sistema universitario fue un propósito asumido explícitamente por las nuevas autoridades educativas (Buchbinder y Soprano, 2008). Para el ministro de la cartera educativa Ricardo Bruera (1976-1977), el llamado "ingreso irrestricto" había producido una "importante infiltración ideológica en las aulas" y un "sobredimensionamiento" de la matrícula de estudiantes que concurrían a las universidades "más allá de lo que podían absorber las capacidades físicas y la disponibilidad de los cuadros docentes" (Bruera en Rodríguez et al., 2009a). En ese sentido, diagnosticaban una "deformación de la pirámide educativa" en desmedro de la educación secundaria y primaria ("pirámide invertida") (Diario La Nación, 14/08/1976). Se entendía que era necesario establecer una nueva relación entre los sistemas de educación básica, media y superior; esto exigía reestructurar las dimensiones de la matrícula universitaria.

\footnotetext{
${ }^{1}$ Cf. Buchbinder, 2010: 178-219 passim.
} 
En la UBA, luego de la gestión del rector interventor Alberto Ottalagano (septiembre-diciembre 1974), la matrícula se redujo a 152863 estudiantes en 1975 y cayó nuevamente en 1976, con 146909 inscritos. En esta caída del número de estudiantes debemos considerar las medidas restrictivas impuestas por los rectores que reestablecieron diferentes requisitos de ingreso y también cupos por carrera a partir de 1975. Asimismo, debemos tener en cuenta la trascendencia pública que adquirió el clima de violencia que se vivía en los claustros donde era regular el enfrentamiento entre agrupaciones estudiantiles ligadas a la "Tendencia Revolucionaria" del peronismo o de izquierda, con bandas armadas de derecha vinculadas a la AAA (Alianza Anticomunista Argentina). Sin embargo, esta cifra continuaba siendo preocupante para las nuevas autoridades que veían en la universidad porteña una enorme concentración de estudiantes donde el "caos" se había apoderado de los claustros.

A pesar de ciertas diferencias existentes entre los primeros rectores de la UBA durante la dictadura y los funcionarios del MCE respecto de la necesidad de cierta autonomía universitaria para los claustros, estos actores compartían la preocupación por el crecimiento de la población estudiantil y la necesidad de "re-adecuar" el tamaño de la universidad. Los rectores Alberto Constantini (agosto-septiembre 1976) y Luis Cabral (1977-1978) señalaron que el crecimiento "desordenado y desmesurado" de la población estudiantil era un problema central que había que solucionar pronto. El primero de ellos afirmaba que el ingreso sin restricciones era querer introducir en un avión con capacidad para 100 pasajeros, 300, y esto equivalía a derribarlo (La Opinión, 16/07/1976).

A continuación, entonces, veremos cuáles fueron las respuestas para el problema del "sobre-dimensionamiento" de la UBA. ¿Se trató de políticas únicamente restrictivas o de achicamiento? ¿Se planteó la necesidad de transformar las estructuras universitarias en forma profunda? ¿Qué efectos tuvieron las políticas implementadas en los claustros porteños? ¿Cuál fue la importancia del "re-dimensionamiento" en el "reordenamiento" universitario?

\section{Soluciones para un "gran" problema}

Revertir el crecimiento "desmedido, desordenado, irracional" del sistema de educación superior nacional fue un eje central de la política universitaria de la etapa (Pérez Lindo, 1986; Buchbinder, 2010; Rodríguez, 2015b). El énfasis en la reducción de la matrícula estuvo puesto por los ministros de Educación y fueron ellos, con mayor o menor éxito, los que consecutivamente propusieron planes de "redimensionamiento" para las unidades académicas ya existentes. En términos generales, se limitó el crecimiento de (y se achicaron) las matrículas estudiantiles por diferentes vías, siendo los cupos y la selección por examen los mecanismos más utilizados. Asimismo, durante las gestiones de los ministros Ricardo Bruera y José Catalán (1977-1978), se promovieron proyectos que apostaban al "reordenamiento" y "re-dimensionamiento" vía la "regionalización" del sistema universitario nacional. De este modo, se cerrarían carreras y facultades que se superpusieran en las regiones definidas. Estos proyectos también incluían la departamentalización de las instituciones y la homogeneización de los aspectos académicos a partir del establecimiento de "ciclos de formación". Los mismos no llegaron a concretarse y dejaron de discutirse cuando sus impulsores dejaban el cargo. Por otro lado, se promovió el cierre de carreras de Ciencias Sociales argumentando su peligrosidad ideológica. Bajo la gestión del ministro Juan Llerena Amadeo (1978-1981) se concretó el cierre de carreras en diversas unidades académicas y de la Universidad Nacional de Luján (UNLu), ${ }^{2}$ así como también el arancelamiento de los estudios de grado.

\footnotetext{
${ }^{2}$ Rodríguez (2015b) ha señalado que a pesar de los lineamientos generales el cierre de carreras se negoció individualmente con cada autoridad universitaria, por lo que los resultados fueron dispares. Las estrategias de redimensionamiento tuvieron un momento sobre
} 
En la UBA los proyectos mencionados no tuvieron demasiada influencia e incluso llegaron a ser combatidos por las propias autoridades. Cuando en 1978, el ministro de Educación Catalán anunció su plan de reorganización, el rector Cabral resolvió, junto a los decanos, que esa institución estaba eximida de dar cumplimiento a la resolución apoyándose en la autonomía. Cabral sostenía que desde la universidad porteña no podían admitir que se le impusiese el cumplimiento de normas que "sólo podrían encontrar justificación si se tratara de una casa de estudios carente de la jerarquía científica y docente, de la tradición y del prestigio" (La Prensa, 30/08/1978). ${ }^{3}$

De este modo, el ordenamiento por facultades no fue alterado a la vez que no se cerraron carreras según lo recomendado por el MCE. Recién en 1981, el rector Lucas Lennon (1978-1981) suspendió la inscripción a Ciencias Antropológicas para que pasara a ser una carrera de posgrado (UBA, Resolución 668, 06/10/1980). Incluso Sociología, carrera muy cuestionada por su "peligrosidad ideológica", continuó funcionando, dependiendo directamente del rectorado, aun cuando su matrícula cayó pronunciadamente. De todos modos, como mencionamos, el problema del "sobre-dimensionamiento" de esta casa de estudios era reconocido por sus autoridades, quienes desarrollaron diversas soluciones. ${ }^{5}$

\section{Exámenes de ingreso y cupos}

En septiembre de 1976, el ministro Bruera anunció la implementación del examen de ingreso y la imposición de cupos por carrera, dos medidas que estaban vigentes en algunas universidades desde 1974. Vale destacar que en la UBA regía el sistema de "Año Común" (Resolución 10, 18/10/1974; 47, 16/01/1975). Durante la gestión del rector Julio Lyonnet se conformó una comisión para analizar la posibilidad de incluir un examen de ingreso pero los proyectos no se concretaron (Rodríguez, 2015b). En diciembre de 1975, se dispuso que los rectores definieran cómo saldar el problema abierto por "un desfasaje en la relación docente-alumnos y dificultades de índole académica o de espacio físico" (La Nación, 19/12/1975). En ese marco, durante la breve gestión rectoral de Eduardo Mangiante, se dispuso un cupo de 10500 vacantes justificado según criterios relativos a las capacidades académicas, edilicias y financieras de cada facultad, el número de "recursantes" del primer año y de deserciones (La Nación, 28/12/1975). Todos los aspirantes debían rendir un examen eliminatorio escrito sobre temas desarrollados durante la enseñanza media. No ingresaría quien obtuviera menos de 4 de calificación (UBA, Resolución 2, 18/02/1976). Vale destacar que el cupo establecido era tres veces menor al cupo establecido para el ciclo lectivo 1975, de 29000 plazas (ver tabla 1 y gráfica 1).

saliente con el cierre de la carrera de Cine en la Universidad Nacional de la Plata (UNLP) (Rodríguez et al., 2009a), la Facultad de Ingeniería en Entre Ríos y el cierre definitivo de UNLu en 1980. Ese mismo año, se dispuso la anexión de la Universidad Católica de la Patagonia Don Bosco a la Universidad Nacional de la Patagonia. La única institución con carácter universitario que creó el gobierno de facto fue la Academia de Estudios Policiales, dependiente del Ministerio del Interior, a fines de 1977 (Bertoni et al., 1990).

${ }^{3}$ Por estas diferencias, el presidente de facto Videla ordenó que tanto el ministro Catalán como el rector Cabral abandonasen sus cargos. ${ }^{4}$ Que dicha carrera continuara abierta fue cuestionado desde los sectores católicos, ya que sostenían que allí se mantenían "agazapados en cargos docentes, elementos altamente comprometidos con la subversión apátrida" (Cabildo, "Antropología y subversión”, núm. 16, mayo-junio 1978, en Rodríguez, 2015b). A partir de lo descrito es posible encontrar líneas de comparación con lo acontecido en las universidades de Mar del Plata, San Juan, Tucumán, Rosario y La Plata donde las carreras cerradas fueron en su mayoría de la rama de las Ciencias Sociales y Humanidades que habían desarrollado un perfil crítico (Gil et al., 2015; Rodríguez, 2015a; Águila, 2015; Algañaraz Soria, 2015). Sin embargo, cabe destacar que el rector Gallo priorizó otorgar cupo a las carreras de profesorados que se impartían en la Facultad de Humanidades y Ciencias de la Educación de la UNLP.

${ }^{5}$ También deben considerarse otras medidas como las limitaciones en el mantenimiento de la condición de regularidad por parte de los estudiantes. Desde 1976, todos los alumnos debían aprobar como mínimo dos materias para no quedar libres y ser desafectados (Pérez Lindo, 1986). Sin embargo, no hemos podido acceder a estadísticas que nos brinden datos sobre la proporción de jóvenes afectados por dicha normativa. De este modo, no podemos avanzar en análisis al respecto. 
Ya durante 1976, los rectores de las universidades nacionales (UN) y el ministro acordaron una serie de criterios comunes para establecer las vacantes por carreras: por un lado, las disponibilidades fisicas, de profesores y de recursos presupuestarios, y por otro, las necesidades nacionales y regionales de recursos humanos. Para la selección de los estudiantes "más aptos y con mayor vocación", se considerarían criterios como el "nivel global de madurez intelectual" y el promedio general de la enseñanza media ( $L a O p i^{-}$ nión, 14/09/1976). Los aspirantes debían rendir dos asignaturas consideradas básicas en la carrera elegida y una prueba de comprensión de texto (Rodríguez, 2015b). Asimismo, se continuó exigiendo como requisito para dar la prueba, los certificados de estudios secundarios completos, de domicilio y de buena conducta extendidos por la Policía Federal Argentina (UBA, Resolución 377, 16/12/1976).

Siguiendo la disposición ministerial, a fin del ciclo lectivo de 1976, el rector a cargo de la UBA, Libertario Rabasa (1976-1977), confirmó las vacantes para cada facultad que debían ser completadas a partir de los resultados de una prueba eliminatoria (por orden de mérito entre los que hubieran aprobado el examen). ${ }^{6}$ El cupo de la universidad para 1977 fue establecido en 13845 vacantes para un total de 24983 aspirantes (Diario La Nación, 16/03/1977; 07/04/1977; ver tabla 1 y gráfica 1).

Tabla 1. Matrícula, cupos, aspirantes e ingresantes de la UBA entre 1973-1983

\begin{tabular}{|c|c|c|c|c|}
\hline Año & Matrícula & Ingresantes & Cupos & Aspirantes \\
\hline 1973 & 133272 & 36452 & --- & --- \\
\hline 1974 & 166215 & 40825 & --- & --- \\
\hline 1975 & 152863 & 30423 & 29000 & 33456 \\
\hline 1976 & 146909 & 21059 & 10500 & 27869 \\
\hline 1977 & 134224 & 13312 & 13845 & 24983 \\
\hline 1978 & 117360 & 11829 & 12380 & 40075 \\
\hline 1979 & 114550 & 11142 & 11050 & 46312 \\
\hline 1980 & 108387 & 10700 & 9830 & 38473 \\
\hline 1981 & 110286 & 11760 & 9830 & 39473 \\
\hline 1982 & 102766 & 12719 & 10145 & 41065 \\
\hline 1983 & 106793 & 13476 & 9780 & 44884 \\
\hline
\end{tabular}

Fuente: elaboración propia con base en datos de Pérez Lindo, 1985; Ministerio de Educación, 2015; Rectorado UBA y Diario La Nación (1973-1983).

\footnotetext{
${ }^{6}$ La Facultad de Ciencias Económicas recibiría mayor cantidad de estudiantes con un cupo máximo de 2 500, luego Derecho, Ingeniería y Medicina con 1500 vacantes cada una. Filosofía y Letras y Arquitectura sólo contarían con hasta 1000 ingresantes cada una, mientras que Ciencias Exactas con 950. Agronomía, Veterinaria, Odontología, Farmacia, Psicología y Sociología tenían cupos máximos de entre 300 y 500 vacantes (UBA, Resolución 376, 16/12/1976).
} 


\section{Gráfica 1. Variación en el cupo de ingreso establecido y aspirantes en la UBA (1975-1983)}

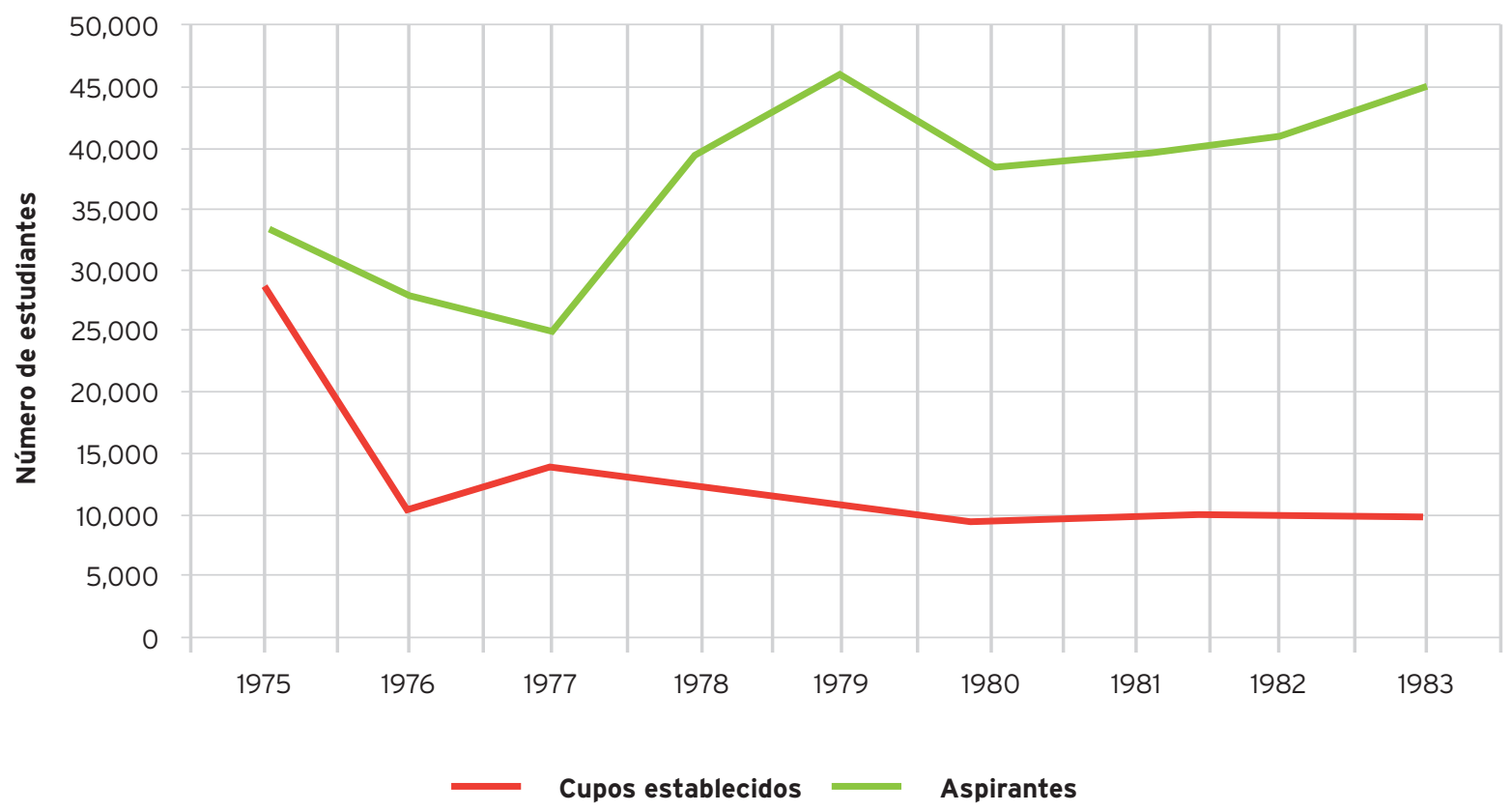

Fuente: elaboración propia con base en datos de Rectorado UBA y Diario La Nación (1973-1983).

De 1977 en adelante, la UBA dispuso que cuando el número de aspirantes a una carrera fuera inferior al número de vacantes establecidas para ella, ingresarían los que hubieran cumplido todas las exigencias de los cursos de apoyo y aprobado las evaluaciones que se fijaran: $80 \%$ asistencia, $100 \%$ de los trabajos prácticos realizados y las calificaciones mínimas para aprobar (UBA, Resolución 825, 28/11/1977; 618, 28/09/1978; 593, 01/10/1979; 411, 08/08/1980). Los aspirantes que no hubieran cumplido la condición anterior, debían rendir examen de las materias correspondientes y obtener no menos de 40 puntos en cada una.

En cambio, cuando el número de aspirantes a una carrera era superior al número de vacantes establecidas, estos debían rendir examen de las materias correspondientes e ingresaban los que resultaran mejor ubicados en el orden de méritos dentro del número de vacantes fijadas. Si se obtenían menos de 40 puntos en alguna asignatura, el aspirante quedaba afuera. Las calificaciones eran inapelables.

Los aspirantes que reunían los requisitos mínimos para el ingreso a una carrera y no accedían a ella por haberse cubierto el cupo respectivo, podían ingresar a otra carrera de la misma área si existieran vacantes, mediante la aceptación del respectivo decano o delegado (UBA, Res. 825, 28/11/1977; 159, 18/04/1978). Quienes no hubieran entrado en un año por falta de cupo y volvían a rendir al año siguiente, contaban con un certificado que les otorgaba un "plus" de puntaje a modo de ventaja o handicap (UBA, Res. 618, 28/09/1978). Los cursos de apoyo para los aspirantes tenían una duración de seis semanas y se realizaban desde fines de enero hasta principios de marzo de cada año. La concurrencia a los cursos de apoyo no era obligatoria (UBA, Res. 825, 28/11/1977). 
En el camino de la "adecuación del sistema universitario" a las "actuales posibilidades de enseñanza" y a las "verdaderas necesidades del país", el ministro Catalán avanzó en el recorte de las vacantes para el ingreso a las universidades nacionales. En paralelo existía un creciente malestar por la situación económica de las universidades (Rodríguez y Soprano, 2009b). Desde el MCE, se dispuso reducir un $24 \%$ el número de vacantes para el ingreso a las 26 universidades. De ese modo, a nivel nacional se pasó de 70000 vacantes en 1977 a 52277 en 1978. En la UBA, se eliminaron 1465 vacantes respecto de 1977, siendo el cupo de 12380 para 40075 aspirantes ( $L a$ Nación, 19/04/1977). En 1979, las autoridades de esta universidad confirmaron que había 46312 inscritos para 11050 vacantes (ver tabla 1 y gráfica 1).? $\mathrm{El}$ tema del ingreso era grave en las grandes universidades pero en ninguna tanto como en la UBA. ${ }^{8}$

En 1980, durante el rectorado de Lennon, en la UBA se aprobó un sistema de ingreso "piloto" en las carreras de Abogacía, Arquitectura e Ingeniería. ${ }^{9}$ El mismo se dictaba durante el año lectivo previo, es decir que durante el segundo semestre los jóvenes cursaban la escuela secundaria en paralelo al curso. $\mathrm{El}$ aspirante que obtuviera por lo menos 4 puntos en cada una de las pruebas parciales de cada materia, y el promedio de esas alcanzara a 7 puntos, quedaría eximido del examen final de la asignatura. Ingresaban los aspirantes que, habiendo finalizado sus estudios secundarios, aprobasen las asignaturas. Esto sin perjuicio de los que ingresaban directamente conforme a las disposiciones (UBA, Res. 123, 31/03/1980). Este sistema continuó funcionando en esas carreras hasta el final de la dictadura.
Ese mismo año, se fijaron 9830 vacantes para 38473 aspirantes (Memorias UBA, 1981). El año siguiente, el cupo se mantuvo, pese a registrarse un incremento de mil inscritos con respecto al año anterior (La Nación, 17/03/1981). En 1982, el número de vacantes aumentó mínimamente alcanzando 10145 (La Nación, 18/03/1982), pero volvió a caer al año siguiente a 9780 para 44884 aspirantes (La Nación, 16/03/1983) (ver tabla 1 y gráfica 1). Estos cambios mínimos en el número de cupos fijados para el ingreso se dieron en el marco de un crecimiento cada vez mayor del número de inscritos: por primera vez en la década de 1980, el número de inscritos superó ampliamente los 40 mil, alcanzando un total de 44 884. En facultades con alta demanda como Medicina, Ciencias Económicas y Derecho las plazas se vieron disminuidas a lo largo de la etapa pero de todos modos continuaron siendo las facultades con mayor número de cupos. Medicina en particular, sufrió un importante recorte pasando de 1500 plazas en 1976-77 y 1750 en 1978, a 800 en 1982-83.

Como se observa a lo largo de la etapa (tabla 1 y gráfica 1), el número de vacantes aceptadas por las autoridades era superado ampliamente por la demanda de los jóvenes que querían cursar sus estudios universitarios. En efecto, según datos procesados por la propia UBA a partir del censo que realizó en 1982, de su población total en ese momento un 93.1\% había entrado en su primer intento, mientras que un $6.9 \%$ lo había hecho en al menos dos intentos. En Medicina, carrera con mayor demanda absoluta y relativa, ese número cae, en tanto que el $89.2 \%$ ingresaron sin tener que rendir más de una vez, mientras que el $8.4 \%$ rindió dos veces y el $2 \%$ lo hizo tres.

\footnotetext{
${ }^{7}$ Mientras La Nación brinda esos datos, las Memorias de la UBA de 1979 precisan que hubo 42351 aspirantes.

${ }^{8}$ En Córdoba la situación no era tan grave ya que se registraban 9530 aspirantes para 4665 vacantes y en La Plata se registraban 7 876 inscritos para 4600 vacantes (Buchbinder, 2015).

${ }^{9}$ Éste se organizaba en tres ciclos: a) presentación y orientación que no era obligatorio ni tenía evaluaciones; b) formación: dictado de un curso de tres asignaturas, una al menos con contenido humanístico, más cursillos o conferencias, cada asignatura, la asistencia era obligatoria y se calificaba a los aspirantes del 0 al 10; c) verificación y evaluación de conocimientos: cada materia tomaba por lo menos dos pruebas parciales escritas y, según el resultado, una final oral.
} 


\section{De "excepciones" $y$ "cuestionamientos"}

$\mathrm{El}$ escenario descrito se vio complejizado cuando la UBA debió hacerse cargo de la población estudiantil de la UNLu luego de su clausura en 1980. A los aspirantes se les permitió inscribirse fuera del cronograma establecido para el examen de ingreso de 1981. Los estudiantes regulares de la UNLu fueron aceptados automáticamente en la UBA (UBA, Res. 1, 29/01/1980); 26, 20/02/1980). Sin embargo, aun cuando se sumaron nuevos aspirantes y una carrera nueva (Tecnología en Alimentos), los cupos establecidos no se modificaron.

A este panorama debemos sumarle algunos elementos más. En primer lugar, debemos considerar que además del cupo establecido todos los años un número de estudiantes accedían por diversos motivos al ingreso directo a las carreras. Para el caso de los egresados de los colegios de la UBA, esto no era una novedad como tampoco para aquellos graduados de otras carreras universitarias. Si es novedoso e interesante de considerar que oficiales de FFAA graduados del Consejo Nacional de Educación Técnica, de la Escuela Superior de Gendarmería Nacional, de la Escuela de Prefectura Naval Argentina Gral. Irigoyen, estaban exceptuados de rendir las pruebas y podían ingresar a las facultades y carreras de la UBA (UBA, Res. 461, 30/12/1976; 460, 21/07/1977; 460, 21/07/1977; 118, 23/03/1979). Por su parte, los aspirantes que se encontraban cumpliendo con el Servicio Militar Obligatorio al momento del examen y lo finalizaban a principio de ese año, podían ser inscritos por un tutor y tenían una plaza reservada de forma condicional. Debían rendir el examen, si lo aprobaban hacían uso de dicho cupo y si reprobaban lo perdían (UBA, Res. 680 y 747, 19/11/1979)..$^{10}$ Asimismo, durante la gestión de
Lennon se definieron 58 escuelas que tenían acceso directo a ciertas facultades: Jesús María e Inmaculada de Buenos Aires, Jesús María, Sagrada Familia y León XIII de la provincia de Córdoba, entre otros (UBA, Res. 58, 29/12/1978). Según los datos que hemos podido relevar en las diferentes fuentes consultadas, entre los años 1977 y 1982, cada año más de mil estudiantes gozaban del ingreso directo a las carreras elegidas. ${ }^{11}$

Este aspecto, que hasta el momento no ha sido considerado por la bibliografía especializada sobre el tema, permite complejizar nuestros análisis sobre las particularidades que tomó el proceso de "re-dimensionamiento" en la UBA. En un primer análisis, podemos observar la relación estrecha y directa que la institución sostenía con las FFAA, llegando incluso a reservar plazas por fuera del cupo establecido para los jóvenes en el Servicio Militar Obligatorio y también para los miembros. Asimismo, el acceso garantizado a los claustros para los miembros de las fuerzas represivas podría darnos una pista de los mecanismos mediantes los cuales se ponía en práctica el operativo represivo en cada facultad. ${ }^{12}$ También podemos dar cuenta del vínculo entre la UBA y las instituciones educativas más prestigiosas y tradicionales dependientes de la iglesia católica. En efecto sus graduados eran "separados" del resto de los aspirantes provenientes de otras escuelas secundarias, fueran públicas o privadas.

Luego, es factible observar la flexibilidad de la política de cupos. Como señalamos, un número considerable de jóvenes accedían a la UBA sin importar el número límite de vacantes establecido. En este sentido vemos la debilidad de ciertas justificaciones del sistema de ingreso basadas en "criterios de racionalidad y disponibilidad de recursos". También pierden

\footnotetext{
${ }^{10}$ También podían pedir turnos especiales de examen (Res. 98, 16/03/1979).

${ }^{11}$ En 1977, ingresaron directamente 1823 estudiantes; en 1978, 1 515; en 1979 contamos con dos cifras, 1 697; en 1980, 1 581. No contamos con la cifra del año 1982. En 1983, hubo 670 ingresos directos (UBA, 1979-1982; La Nación, febrero, marzo y abril de 1977-1983). ${ }^{12}$ Numerosos testimonios relatan la presencia de vigilancia vestida de civil perteneciente a diferentes fuerzas. Estos actores se hacían pasar por estudiantes y entraban a las clases con la finalidad de observar el comportamiento de los estudiantes y docentes.
} 
peso los argumentos esgrimidos acerca de la necesidad de una "selección" entre los jóvenes más "aptos" para desarrollar estudios universitarios en función de la evaluación de su "madurez intelectual", "capacidades" y "actitudes".

A partir de lo planteado se vuelve evidente que los objetivos de la política de "re-dimensionamiento" tenían como objetivo principal el simple achicamiento de la matrícula de la casa de estudios que tantos conflictos había generado. De este modo, el proceso de "re-dimensionamiento" universitario deja de ser un proceso monolítico. Por un lado, es clara la búsqueda deliberada de achicamiento de la estructura universitaria. Por otro, debemos considerar que a pesar de que miles de jóvenes quedaban fuera de la UBA año a año, también existieron mecanismos por los cuales ciertos grupos lograron acceder a las carreras sin pasar por las pruebas. Esto era posible en función de su pertenencia institucional previa. Así, el "re-dimensionamiento" se entrecruzaba con mecanismos de selectividad social, cultural e ideológica.

Tal como ha señalado Buchbinder (2015), "la cuestión del ingreso" constituyó uno de los temas relativos a la vida universitaria más atendidos por la prensa. A pesar de que en general había acuerdo respecto de la necesidad de regular y restringir el ingreso a las casas de estudio, también se cuestionaban las fallas en la organización de los cursos y exámenes, así como se destacaba el número elevado de jóvenes que no podían acceder a los estudios universitarios (La Nación, 06/03/1978; 21/03/1978; 17/01/1983). En testimonios recogidos por la prensa, ingresantes a las carreras de Filosofía y Letras afirmaban que el examen había sido "objetivo", "fácil" y "sin sorpresas", acorde a lo trabajado en los cursos. Los cursos eran el aspecto más cuestionado: la limitación horaria para quienes trabajaban y la brevedad de los mismos. Asimismo, varios resaltaron que consideraban mejor la modalidad "piloto" de Derecho y otras facultades con cursos más largos a pesar de la exigencia que suponía continuar los estudios secundarios y, en paralelo, seguir el curso para el ingreso. Primaba la idea de que si se estudiaba se podía ingresar a la facultad porque el examen no era "tramposo". Más allá de cuestionamientos puntuales a la logística, La Nación afirmaba que las pruebas se tomaban con "normalidad" (La Nación, 19/03/1978).

En carreras como Medicina o Ciencias Económicas la situación era diferente ya que allí la demanda era mucho mayor y las vacantes disponibles dejaban a muchos aspirantes afuera. Para ello, se establecía un promedio alto como mínimo para ingresar, quedando eliminados jóvenes que habían aprobado los exámenes, incluso con buenas calificaciones. Se dieron casos individuales en que los aspirantes presentaban recursos ante la Justicia para que se permitiera su ingreso a la carrera (La Nación, 10/04/1977). Desde rectorado, se autorizó en varias ocasiones que ingresaran mayor número de estudiantes que lo establecido por el cupo considerando promedios iguales, por ejemplo. Así, entre 1979 y 1983, ingresaron efectivamente un número superior al cupo. ${ }^{13}$ Como se observa a medida que el régimen se debilitaba y la movilización estudiantil aumentaba, los cupos fueron más flexibles.

En los espacios institucionales pautados para el diálogo entre el rector Lennon y estudiantes destacados de cada facultad, los cuestionamientos por parte de los alumnos al sistema de ingreso se focalizaban en aspectos organizativos, mientras que no era cuestionada ni la existencia de pruebas ni de cupos. La necesidad de un mecanismo de "selección" de los aspirantes para evitar el crecimiento "desmedido" de la matrícula era una idea aceptada y compartida al menos por los jóvenes seleccionados para conversar con la máxima autoridad de la casa de estudios (Lennon, 1979; 1980; 1981).

\footnotetext{
${ }^{13}$ En 1979, ingresaron 11142 en lugar de 11 050; en 1980, 10700 en vez de 9 830; en 198112071 y no 9 830; en 1982 , 14650 y no 10145.
} 
Este aparente consenso generalizado sería puesto en cuestión en 1981 con la progresiva revitalización de la movilización estudiantil que tomó como una de sus principales consignas la condena a los cupos y la exigencia de "ingreso irrestricto". Vale dejar abierto el interrogante de por qué dicha reivindicación tomó protagonismo.

El momento del ingreso es recordado por quienes estudiaron en esos años por haber sido un momento más o menos determinante en sus trayectorias. Entre quienes provenían de colegios dependientes de la UBA, la transición era directa, sin exámenes ni cupos. Para los que rindieron el examen fue un momento más o menos complicado, en efecto, no todos lograron pasar los filtros en primera instancia y debieron volver a rendir el año siguiente (entrevistas a G. Bilmes, 2015 y M. Giurlanda, 2015). Ante esta posibilidad, varios de los individuos entrevistados rindieron exámenes de ingreso en una institución alternativa ante el "riesgo" de no lograr ingresar a la UBA y "perder el año" (entrevistas a J. Cernadas, 2015; M. Giurlanda, 2015 y S. Sánchez, 2015). En la universidad porteña era una posibilidad real quedarse afuera por falta de cupo o por no aprobar las materias establecidas. En ese sentido, rendir más de una vez los exámenes también era algo pensable y una realidad para numerosos jóvenes, como así también desarrollar planes alternativos en tanto sólo algunos accedían a las carreras.

A pesar de que desde Rectorado y el MCE no había una política de diálogo con las polémicas mencionadas, las autoridades realizaban regularmente declaraciones defendiendo el sistema. Las restricciones se justificaban en la búsqueda de un mejoramiento de la calidad educativa, en relación con la planificación del crecimiento del sistema universitario y de la selección de los alumnos con "aptitud universitaria" y "madurez espiritual", rasgos que no se deducían automáticamente de la condición de egresado de la enseñanza media (La Nación, 01/03/1980, 05/03/1980, 24/03/1980; Esquiú Color, 5-11/9/1982; Clarín, 20/03/1983; Tiempo Argentino, 03/04/1983; La Voz, 03/04/1983; Lennon, 1980). De este modo, los motivos que imponían los cupos eran fundamentalmente académicos y remitían además a limitaciones edilicias y administrativas. Es interesante detenernos en esta respuesta ya que la misma se aleja de la idea extendida de que la política "limitacionista" obedecía a una determinación previa del número de profesionales motivada a su vez en las necesidades del país.

\section{Arancelamiento}

Con la sanción de la nueva ley universitaria en $1980,{ }^{14}$ se dejó abierta la posibilidad de arancelar los estudios de grado en las universidades nacionales (UN). En la UBA en particular ya tenían esta modalidad los cursos de graduados dictados en las distintas facultades así como una serie de servicios y trámites a los cuales, en general, todos los estudiantes necesitaban acceder (fotocopias, certificados, legalizaciones, uso de computadoras y laboratorios, realización de análisis de laboratorios, actividades deportivas, jardín maternal, etcétera). Estos montos se actualizaron constantemente en paralelo al proceso inflacionario que atravesaba el país y a la caída del presupuesto universitario (UBA, Res. 686, 01/11/1979; 769, 10/11/1979; 245, 20/05/1980; 367, 11/07/1980; 516, 08/09/1980; 769, 10/11/1980; 805, 28/11/1980; 908, 19/12/1980; 207, 19/05/1981; etcétera).

La política de arancelamiento es considerada por Cano (1985), Buchbinder et al. (2008), Rodríguez et al. (2009a), Rodríguez (2015b), como otra de las modalidades que adquirió la política de "re-dimensionamiento" del sistema universitario. Es necesario interrogarnos en qué medida la imposición de cuotas en la carrera de grado implicó un "achicamiento" de la matrícula ya que numerosos entrevistados

\footnotetext{
${ }^{14}$ Sobre la sanción y la aplicación de la ley 22207 en la UBA, ver Seia, 2017. Cf. Rodríguez, 2015b.
} 
afirmaron que se trataba de un monto "ínfimo" e incluso "irrisorio" o bien que el cumplimiento con el pago era irregular. De todos modos, es posible afirmar que se trató de una medida regresiva en tanto el nivel de grado era gratuito desde mitad de siglo y había sido un factor importante en el crecimiento de la matrícula universitaria.

En ese momento, desde la Revista Criterio (núm. 1799, 1979), se interpretaba que la propuesta de arancelamiento contaba con la simpatía y el decidido apoyo del Ministerio de Economía, "empeñado" en reducir drásticamente el gasto público corriente y en limitar el nivel de inversión pública. Asimismo, esta medida era sostenida por los rectores de las UN ante la escasez de recursos financieros con los que contaban. El autor del artículo afirmaba que la reducción de la parte del presupuesto nacional consagrado a la educación en los últimos años había sido sustancial. Se afirmaba que el "achicamiento" producto de las restricciones al ingreso impuestas en tiempos recientes no se había traducido en una disminución de los costos totales. En parte, esto se debía a que las principales universidades estaban "sobre-dimensionadas" en términos de alumnos y, en parte, porque no había habido ningún intento de racionalización de la vida académica, traducida en una reducción de costos. De este modo, las casas de estudio tenían cada vez menos margen de maniobra, casi todo el presupuesto debía dedicarse a gastos de funcionamiento.

$\mathrm{Al}$ respecto, Cano (1985), Rodríguez et al. (2009) y Rodríguez (2015b), entre otros, sostienen que se trató de una medida pensada como un paliativo a la dificultosa situación económica que atravesaban las UN producto de una caída del aporte del Estado nacional en su presupuesto. ${ }^{15}$ Vale detenernos en este punto, ya que observamos que el aporte fiscal del Estado nacional a las UN, cayó bruscamente en 1976 y 1977, para luego recuperarse y oscilar por debajo de los valores históricos hasta entonces registrados. Sin embargo, dada la política de limitación del acceso a las UN, se alcanzaron valores relativamente significativos en la asignación de recursos por alumno, a excepción de los años 1976 y 1977 (Bertoni et al., 1990: 21). El presupuesto de la UBA (considerado a valores constantes de 1980 en millones de pesos ley 18 188) tuvo momentos de alzas y bajas en su asignación. Mientras que en 1976 recibió 293606 pesos, en 1977 obtuvo 257 837. Luego, en 1978, 1979 y 1980 aumentó su asignación, ya que según la programación presupuestaría recibió 337 857, 355489 y 435690 pesos, respectivamente. En 1981 y 1982, según los datos disponibles en el libro de Cano, recibió unas cifras inferiores: 393190 y 318877 pesos (Cano, 1985). Si bien en términos absolutos las asignaciones aumentaron, debemos considerar el proceso inflacionario que atravesó el país así como también que los montos asignados eran destinados en su totalidad a garantizar el funcionamiento de la institución.

En ese marco, el rectorado de la UBA dispuso en noviembre de 1979 que los aspirantes que se inscribieran para el ingreso 1980 debían abonar la suma de 5000 pesos (de ese momento) en concepto de reintegro de gastos. En los casos en que los aspirantes invocaran la imposibilidad de abonar la suma mencionada, los decanos de las facultades y delegados

\footnotetext{
${ }^{15}$ Mientras la participación en el PBI del gasto en educación universitaria, entre 1973 y 1975 era de $0.81,0.87$ y 0.77 ; entre 1976 y 1983, el porcentaje de la participación del gobierno nacional en el gasto en educación universitaria no llegó nunca al 0.7: 0.43; 0.42; $0.59 ; 0.58 ; 0.68 ; 0.65 ; 0.51 ; 0.69$, respectivamente. La participación del MCE en el presupuesto total de la administración pública, tras un aumento de 4.1\% entre 1973 (11.6) y 1974 (15.7), descendió y no volvió a superar el 13\%: en 1975 tuvo el 13.1; en 1976 el 6.9; en 1977 el 7.3; 1978 el 9.0. En 1979 recuperó lugar y logró el 13\%, mientras que los tres años siguientes tuvieron valores inferiores: 10.3\% (1980), 11.6 (1981); 10.5 (1982) y 8\% (1983) (Cano, 1985: 164). Mientras en 1973, 1974 y 1975 el aporte fiscal aumentó respecto de 1972 (4 360.7), con un suma de 5 722.5, 6 545, 2 y 6 061.6, respectivamente. En 1976 y 1977 se da una caída abrupta: 3215.8 y 3228.4 millones de australes cada año. Entre 1978 y 1980 se da un progresivo mejoramiento: 4 305.6, 445.4; 5 410, 5410 . Entre 1980 y 1983 , los valores caen un poco: 4 456, 3296.1 y 4632.2 (datos presentados en millones de australes a valor de 1988, Secretaria de Hacienda de la Nación, elaboración de los autores, Bertoni y Cano, 1990).
} 
de las carreras quedaban autorizados a eximir del pago correspondiente si consideraban atendibles las razones invocadas (UBA, Res. 775, 26/11/1979). Quienes se inscribieron en 1980 para el ciclo lectivo de 1981 debieron abonar 10000 pesos (UBA, Res. 797, 27/11/1980).

En 1981, luego de la sanción de la nueva ley universitaria que dejaba abierta la posibilidad de arancelar los estudios de grado, rectorado aprobó los aranceles para las facultades de Ciencias Exactas e Ingeniería. Por un lado, se encontraba la "matricula anual de estudiante" con un valor de 12000 pesos y por otro, la "matrícula anual de profesionales" de 24000 pesos cobrada a los graduados. El pago de la misma, los habilitaba al uso del servicio del departamento becas y prácticas profesionales (UBA, Res. 110, 31/03/1981). Luego, se definieron los aranceles en el resto de las facultades y carreras de la UBA (UBA, Res. 95, 20/03/1981). Se estableció también que aquellos estudiantes becarios de la universidad iban a quedar eximidos del pago (UBA, Res. 300, 27/05/1980; 279, 25/05/1981; 288, 03/06/1981; $301,27 / 05 / 1981) \cdot{ }^{16}$

Según la normativa, las sumas recaudadas en concepto de arancel, recargos por mora y tasas de expedición de duplicado de la libreta de pagos, se aplicarían a la financiación del sistema de becas y subsidios de la universidad, previa deducción de los gastos que representaban los costos directos de implementación y control de arancelamiento. El excedente, si lo hubiere, se destinaría a la adquisición de material de enseñanza y equipamiento de bibliotecas; financiación de actividades de extensión; etcétera (UBA, Res. 480, 03/08/1981). ${ }^{17}$

\section{Los efectos del "re-dimensionamiento""18}

Las combinaciones de medidas restrictivas impuestas desde el MCE incidieron significativamente en la evolución de la matrícula (Buchbinder et al., 2008). En términos generales, Cano y Bertoni han señalado que la re-instauración de pruebas de ingreso en las UN que rechazaban en promedio al $50 \%$ de los aspirantes a ingresar junto al clima general de deterioro de la labor docente y de investigación, contribuyeron primero a un brusco descenso, y luego a un estancamiento de la matrícula, en tanto que paralelamente creció el número absoluto y relativo de inscritos en las universidades privadas ${ }^{19}$ y en los institutos terciarios no universitarios. Según los datos brindados por Pérez Lindo, la matrícula total del sistema universitario argentino cae de 518000 alumnos en 1976 a 394000 en 1980, para luego recuperarse lentamente y llegar a 416000 estudiantes en 1983 (ver gráfica 2). ${ }^{20}$

\footnotetext{
${ }^{16}$ Respecto del plan de becas para estudiantes, la beca sería adjudicada por 10 meses. La facultad le asignaría a cada becario un consejero de estudios que tenía como obligaciones: aprobar el plan de actividades académicas presentado anualmente por el alumno, aconsejar al becario en todo aquello que se relacionara en forma directa con sus estudios, informar cada dos meses el rendimiento académico del becario, etcétera. (UBA, Res. 617, 06/10/1981).

${ }^{17}$ Es importante destacar que la aplicación del arancel en los estudios de grado estimuló la activación del movimiento estudiantil porteño que participó de campañas de recolección de firmas, movilizaciones y "quema de chequeras" (el comprobante de pago) contra dicha disposición (Seia, 2016b).

${ }^{18}$ En el presente apartado no hemos considerado datos acerca del número de egresados y las tasas de graduación en la UBA y en las UN en la etapa que analizamos en tanto no hemos logrado obtener datos sobre todos los años en cuestión que nos permitan contrastar los presentados por Pérez Lindo (1986:183) y corroborar ciertas tendencias. Vale destacar, sin embargo, que el mencionado autor destaca que la tasa de graduación y el número de egresados en términos absolutos aumentaron durante la última dictadura. Consideramos que estos datos merecen reflexiones específicas más profundas en próximos trabajos acerca de los efectos de la política universitaria entre 1976 y 1983.

${ }^{19}$ En 1976 el sistema privado concentraba unos 57136 estudiantes (el 12\% de la matrícula total) y en 1982 llegaba a 75211 (19\% de la matrícula total) (Datos de la CONADE, MCE, CRUN en Pérez Lindo, 1985: 215).

${ }^{20}$ Se observa una tasa de crecimiento negativa de la matrícula universitaria entre los años 1976 y 1978, mayor al diez por ciento. Hasta 1983 no se recuperaron los valores de 1975. La tasa de crecimiento de la matrícula estudiantil era constante hasta 1975, desde 1976 la tasa es negativa -0.8\%; en 1977: -12.6; en 1978: -14.1\%. Recién en 1982, la tasa de crecimiento universitario retoma un índice positivo: 2.2\% (Pérez Lindo, 1985: 216).
} 


\section{Gráfica 2. Variación de matrícula estudiantil en la UBA y en las UN (1968-1982)}

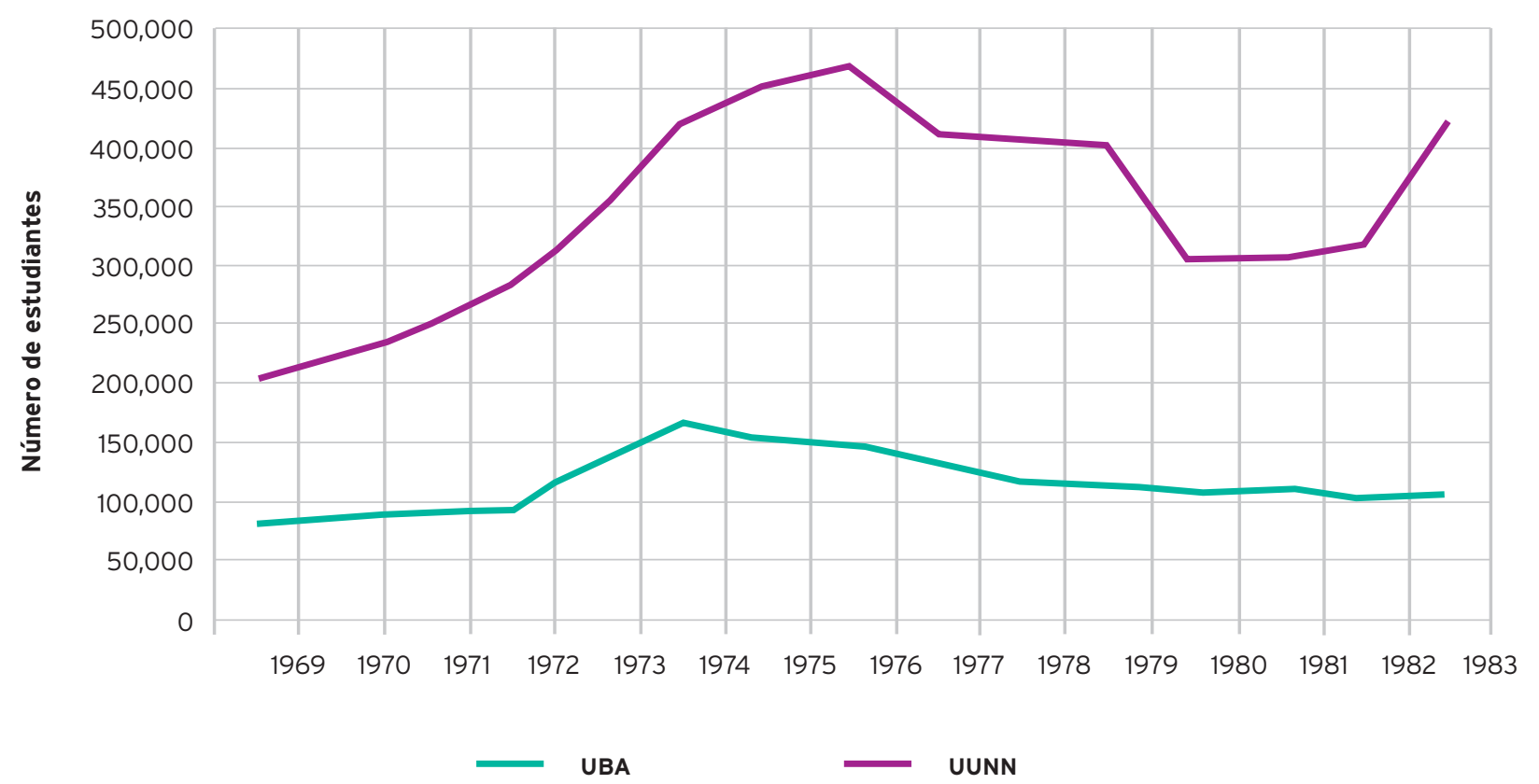

Fuente: elaboración propia con base en datos de Pérez Lindo (1986) y Secretaría de Políticas Universitaria, Ministerio de Educación (2015).

Como lo muestran la tabla 1 y la gráfica 2 , en la UBA la matrícula total era de 133272 estudiantes en 1973 y 166215 en 1974. En 1975 esta cayó a 152 863 y desde entonces se observa una caída sostenida en términos absolutos entre 1976 y 1980; de 146909 estudiantes se llegó a 108 387. En 1981, se observa un aumento (110 286 alumnos) pero en 1982 volvió a caer significativamente llegando a su nivel más bajo de la etapa con 102766 estudiantes. En 1983 se recuperó hasta los $106793 .{ }^{21}$

Respecto del número de ingresantes, a nivel general en las UN, durante 1975 se observa un 25\% menos de estudiantes respecto del año anterior. En los dos años siguientes, se sostuvo el descenso del número de ingresantes, en 1976 entró un 13.1\% menos que en 1975 y en 1977, un 104.8\% menos que el año anterior. En los años posteriores observamos cierta recuperación pero de ningún modo se alcanzan los niveles de ingreso de 1974 o los años previos (ver gráfica 3). ${ }^{22}$ Siguiendo los datos presentados por Daniel Cano, cabe destacar que si bien el descenso más brusco (de casi 90.000 a menos de 45 000) correspondió al año 1977, es decir, ya bajo plena vigencia de la política universitaria de la última dictadura, el relevo ministerial durante el anterior gobierno constitucional marcó el cambio de signo en la política de ingreso a la universidad. Los valores de nuevos inscritos, si bien se mantuvieron en un nivel

\footnotetext{
${ }^{21}$ En 1977 la matrícula fue de 134 224, en 1978 de 117 360, en 1979 de 114 550. Todos estos datos fueron brindados por la Secretaría de Políticas Universitarias (2015).

${ }^{22}$ En 1974 ingresaron 127606 estudiantes; en 1975, 101 784; en 1976, 89 952; en 1977 43 924; 1978, 48 623; en 1979, 49 767; en 1980, 50402 y en 1981, 50 644. (Cano, 1985: 141).
} 
elevado, comenzaron a declinar. Para comprender dicha tendencia debemos considerar factores como la política restrictiva dispuesta, las cesantías masivas de docentes y los elevados niveles de violencia de las facultades.

En la UBA (gráfica 3), en 1973 y 1974 ingresaron 36452 y 40825 estudiantes respectivamente; desde 1975 este número descendió a 30 423; en 1976 a 21 059; en 1977 llegó a 13 312/11 073; en 1978 a 13 127/11 829; en 1979 fue de 12 555/11 142; en 1980 de 12 146/10 700; 11 760/12 071 en 1981; y, 12 719/14 650 en 1982. ${ }^{23}$ A pesar de las diferencias entre los datos obtenidos, consideramos que es posible observar una clara tendencia de disminución del número absoluto de ingresantes a la UBA a lo largo de todo el periodo, con una leve recuperación hacia el final.
Coincidimos con la afirmación de Buchbinder et al. (2008) acerca de cómo la política de cupos contribuyó a bajar la cifra total de alumnos. En el caso de la universidad porteña esto es un dato que sobresale al considerar los efectos de la política universitaria durante los años que estudiamos. La mayor distancia entre aspirantes, número de aprobados en los exámenes y vacantes disponibles se dio siempre en casi todas las carreras de esa universidad. Se calculaba que sólo uno de cada cuatro inscritos podía entrar. Esta selección, cuya finalidad última no era identificar a los mejores candidatos sino reducir el tamaño de las UN, generó una demanda social insatisfecha de los jóvenes en edad de estudiar en la universidad que se movilizó hacia el final de la etapa dictatorial (Seia, 2016a), logrando en algunas facultades como Medicina, Ciencias Exactas o Psicología

\section{Gráfica 3. Variación de número de ingresantes a UBA y UN (1974-1982)}

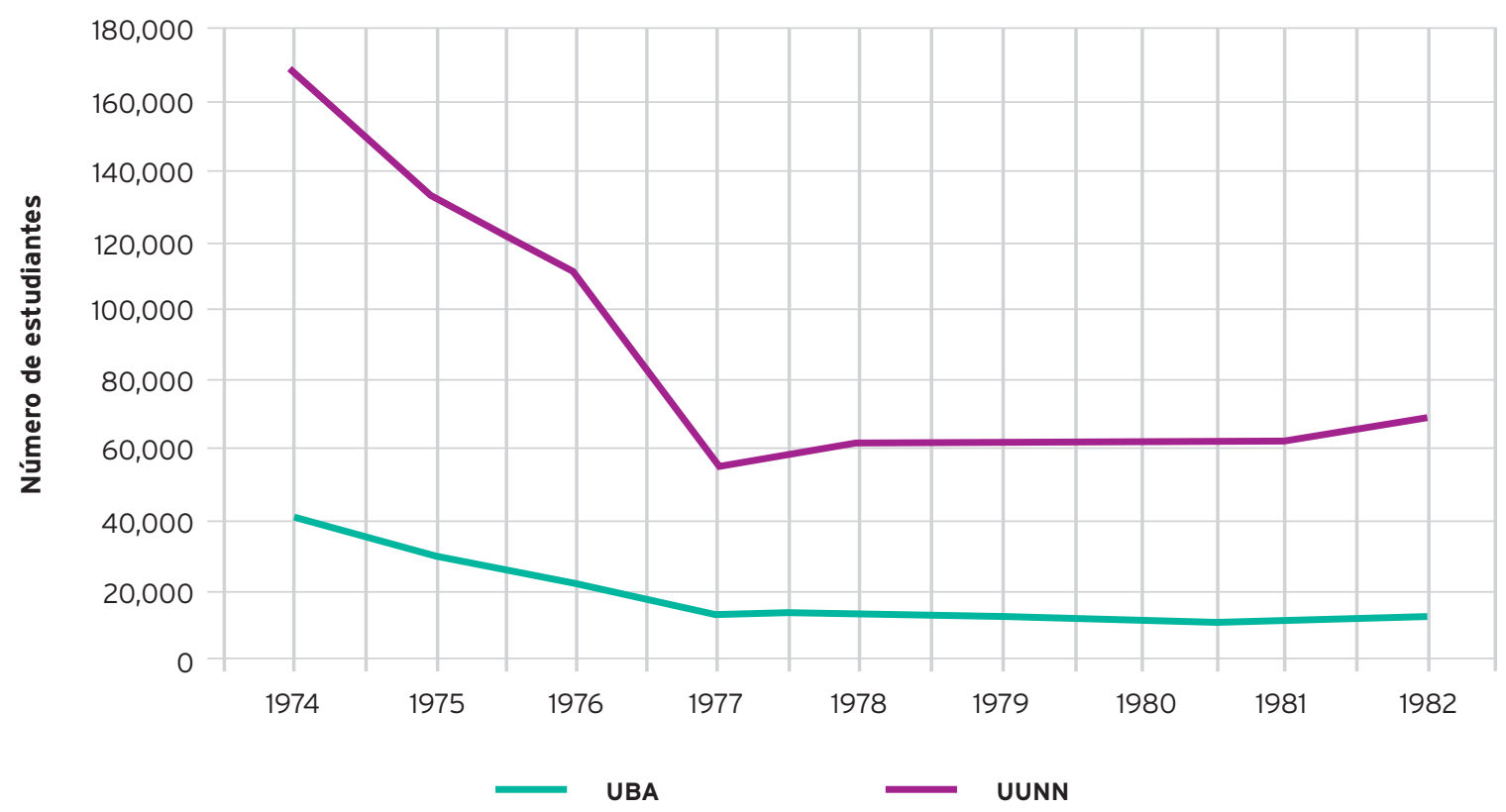

Fuente: elaboración propia en base a datos brindados por Cano (1985), Pérez Lindo (1986) y La Nación (1975-1983).

\footnotetext{
${ }^{23}$ A partir de las fuentes consultadas disponemos de los datos aportados por Pérez Lindo y separados por una barra aquellos recolectados por nosotros en la prensa y a partir de las Memorias editadas por el Rectorado.
} 
que quienes hubieran aprobado el examen ingresaran a pesar de estar cubierto el cupo, sobre todo en los casos de empate de puntajes.

\section{A modo de cierre}

Pérez Lindo (1985) ha señalado que durante esta etapa se buscó conseguir, con un cuerpo docente "depurado" y un estudiantado sometido a varios mecanismos de selección, un sistema universitario "más pequeño, más eficaz, más controlable”. Propone que la política "limitacionista" del régimen tiene que ser analizada en un doble nivel: ideológico y social. Respecto del primero, sostiene que desde el punto de vista de los profesores y de los estudiantes, se trató de impedir la presencia en la universidad de "individuos subversivos". Así, se justificaba la represión, la arbitrariedad y la intimidación. El objetivo era la creación de una comunidad universitaria obediente y desmovilizada. Desde el punto de vista social, las limitaciones al ingreso apuntaban a disminuir la masa de la población estudiantil, objetivo logrado en el caso porteño.

Sin embargo, debemos complejizar la idea del autor respecto de que el achicamiento de la universidad fue una de las metas de la dictadura en conjunto con la política de "achicamiento" económico general, en tanto consideramos que los objetivos de estas medidas definidas desde el MCE y el rectorado, estaban orientadas por una perspectiva en que la universidad masiva y reformista representaba una "amenaza" para el orden social. En efecto, más allá de la simpatía que desde la cartera económica podía traer el "re-dimensionamiento universitario" las metas de quienes desarrollaron estas políticas universitarias se fundaban en una concepción más conservadora y tradicional del papel de la universidad y no en metas "racionalizadoras" y "eficientistas" de corte (neo)liberal. En todo caso, estos funcionarios debieron adaptarse, no sin quejas, a un exiguo presupuesto y buscar alternativas para la financiación como el cobro de diversos aranceles. En este punto, consideramos necesario matizar la identificación de similitudes en los fundamentos neoliberales de la política de "re-dimensionamiento" planteada por Rodrigo Patto Sá Motta (2015) entre la política universitaria de la última dictadura argentina y la de Pinochet en Chile.

La propuesta para la universidad de la última dictadura fue básicamente de achicamiento en un sentido liso y llano. Si el problema era su "sobre-dimensionamiento" la respuesta era la reducción de su matrícula para disminuir los riesgos de la movilización y el descontento. En universidades menos pobladas también era más fácil y profundo el control y la vigilancia sobre los jóvenes. De este modo, es factible que afirmemos que la propuesta universitaria del autodenominado "Proceso de Reorganización Nacional" fue considerablemente menos "creativa" que la de la dictadura anterior en Argentina. Al respecto de esta última, Mariana Mendonça (2015) ha descrito que la concentración de la población estudiantil en las principales ciudades del país era una preocupación principal para los ministros de la "Revolución Argentina". Sin embargo, luego de que los movimientos de masas de 1969 plantearon soluciones a este "problema", alternativas a la represión y a la reducción se debía avanzar en la reconfiguración del sistema universitario, todo a partir de la creación de nuevas universidades lejos de los centros urbanos densamente poblados y de las universidades más antiguas, de modo de distribuir la demanda de educación superior a lo largo y ancho del país (Mendonça, 2015). Asimismo, se buscó estimular la creación de otros centros de educación superior no-universitaria.

Estrategias similares pusieron en marcha los militares y civiles que encabezaron la dictadura en Brasil desde 1964 (Patto Sá Motta, 2014). El "problema universitario" para los funcionarios brasileños no era solamente político sino también académico, científico y de desarrollo nacional, por lo que se apostó a una reforma y modernización del sistema de educación superior creando nuevas instituciones, abriendo más 
plazas en las existentes, promoviendo la carrera de docencia e investigación, entre otras medidas.

Estos someros contrapuntos que de ningún modo pueden agotar el ejercicio de comparación, nos permiten ilustrar el carácter de la política universitaria aplicada en la UBA durante la última dictadura. Para los civiles y militares que se ocuparon del ámbito educativo la universidad era básicamente un problema político. De este modo, la transformación del sistema universitario pasaba únicamente por la "depuración de los claustros de la amenaza subversiva", la desmovilización y despolitización de la comunidad, dejando atrás la herencia reformista y el achicamiento de la casa de altos estudio más densamente poblada del país. A la universidad no le atribuyeron otros objetivos o metas que la formación moral y profesional de los jóvenes de la patria, tampoco adquirió un papel relevante en el desarrollo nacional ni en la investigación.

Por último, es interesante destacar las líneas de continuidad en los diagnósticos de "sobre-dimensionamiento" y las respuestas a dicho problemas planteadas por los funcionarios de la cartera educativa del gobierno peronista anterior al golpe de estado de marzo de 1976. Tal como hemos descrito en el presente texto, aparecen argumentos compartidos entre las autoridades dictatoriales y sus antecesores. La búsqueda de una reducción de la matrícula estudiantil universitaria no puede ser entendida como una novedad de 1976, sino como un punto de la agenda de la política educativa en el combate contra la "penetración subversiva". De todos modos, debemos tener presente que la aplicación de medidas restrictivas entre 1974 y 1976 no fue homogénea a todas las casas de estudio. En ese sentido, es necesario precisar que la caída de la matrícula desde 1974 es una tendencia propia de la universidad porteña. En cambio, a nivel nacional, ese fenómeno se observa a partir de 1976. El sistema universitario argentino es extenso, heterogéneo y complejo, por ello debemos continuar realizando trabajos sobre casos nacionales que nos permitan construir un conocimiento acabado del pasado universitario reciente. 


\section{Referencias}

\section{Diarios, revistas y otras publicaciones}

Diario La Nación, 1976-1983, Buenos Aires.

Diario La Opinión, 1976, Buenos Aires.

Diarios La Voz, Clarín, Tiempo Argentino, Esquiú Color, La Prensa, 1982-1983. Buenos Aires. Recortes seleccionados y agrupados por la Secretaria de Prensa de la UBA.

Revista Criterio, núm. 1 799, noviembre de 1979, Buenos Aires.

\section{Documentos oficiales}

Secretaría de Políticas Universitarias, Departamento de Información Universitaria (2015), "Serie de estudiantes de la Universidad de Buenos Aires. Años 1973-1983", Buenos Aires, Secretaría de Políticas Universitarias, Ministerio de Cultura y Educación (MCE).

Poder Ejecutivo Nacional (PEN) (1976), "Bases para la intervención de las fuerzas armadas en el proceso nacional", Buenos Aires.

PEN(1980), Ley 22.207. “Ley orgánica de las universidades nacionales", Buenos Aires.

Universidad de Buenos Aires (UBA) (1974-1983), Discursos de autoridades, Comunicados de Prensa, Antecedentes y Curricula Vitae de Ministros de Educación y Cultura (Pedro Arrighi), Rectores de la UBA (Lucas Lennon) Buenos Aires, Rectorado y Secretaría de Prensa y Difusión, UBA.

UBA, Rectorado (1979-1982), Memorias de la UBA, Buenos Aires, Rectorado, UBA.

UBA, Rectorado (1974-1983), "Resoluciones Rectorales", Buenos Aires, Rectorado, UBA.

\section{Testimonios}

Entrevistas realizadas a María Giurlanda, Sara Sánchez, Víctor Cipolla, Jorge Cernadas, Gabriel Bilmes, realizadas por G. Seia durante 2015, Buenos Aires.

\section{Bibliografía}

Águila, Gabriela (2015), "La Universidad Nacional de Rosario en dictadura (1976-1983): depuración, 'normalización' y reestructuración institucional', en PolHis, año 7, núm. 14, Mar del Plata, <http:// historiapolitica.com/2015/06/17/3005/> [Consulta: 13/01/2017].

Algañaraz Soria, Víctor (2015), "Reestructuración universitaria en clave autoritaria: política y accionar de los rectores de la Universidad Nacional de San Juan durante la última dictadura militar (1976-1983)", en PolHis, año 7, núm. 14, Mar del Plata, <http:// historiapolitica.com/2015/06/17/3005/> [Consulta: 13/01/2017].

Bertoni, María et al. (1990), "La educación superior en la Argentina en los últimos veinte años: tendencias y políticas", en Revista Propuesta Educativa, núm. 2, año 2, Santiago de Chile, Fondo de Cultura Económica.

Buchbinder, Pablo (2015), "La Universidad de Buenos Aires bajo la dictadura: una aproximación a través del perfil, discurso y propuestas de dos de sus rectores", en XI Jornadas de Sociología, FSOC, Universidad de Buenos Aires, Buenos Aires, en prensa.

Buchbinder, Pablo (2010), Historia de las universidades argentinas, Buenos Aires, Sudamericana.

Buchbinder, Pablo et al. (2008), Masividad, fragmentación y heterogeneidad; el sistema universitario argentino 1983-2008, Buenos Aires-Los Polvorines, Biblioteca NacionalUNGS.

Califa, Juan Sebastián y Guadalupe Seia (2017), "La ampliación del sistema universitario argentino durante la 'Revolución Argentina'. Un estudio de sus causas a través del caso de la Universidad de Buenos Aires (1969-1973)", en A Contracorriente, vol. 15, núm. 1, Carolina del Norte, <http://acontracorriente. chass.ncsu.edu/index.php/acontracorriente/article/ view/1620> [Consulta: 15/01/2018].

Cano, Daniel (1985), La educación superior en la Argentina, Buenos Aires, FLACSO-CRESALC/UNESCO, Grupo Editor Latinoamericano.

Comisión Nacional sobre la Desaparición de Personas 
(CONADEP) (1984), Informe Nunca Más, Argentina. <http://www.derechoshumanos.net/lesahumanidad/ informes/argentina/informe-de-la-CONADEPNunca-mas.htm> [Consulta: 15/01/2017].

Duhalde, José Luis (2013), El Estado Terrorista Argentino, Buenos Aires, Colihue.

Gil, Gastón et al. (2015), “Continuidades, 'orden' y 'despolitización'. La Universidad Nacional de Mar del Plata en los años de dictadura (1976-1983)", en PolHis, año 7, núm. 14, Mar del Plata, <http://historiapolitica. com/2015/06/17/3005/> [Consulta: 13/01/2017].

Mendonça, Mariana (2015), "Cómo resolver el problema universitario: nuevos diagnósticos y cambios en la agenda política durante el Onganiato (1966-1970)”, en Revista Historia da Educaçao, vol. 19, núm. 47, septiembrediciembre, Santa María, <http://148.215.1.176/ articulo.oa? id=321641513015> [Consulta: 13/01/2017].

Orbe, Patricia (2015), “El 'proceso de reorganización’ de los claustros: el impacto político-educativo de la última dictadura en la Universidad Nacional del Sur", en PolHis, año 7, núm. 14, Mar del Plata, <http:// historiapolitica.com/2015/06/17/3005/> [Consulta: 13/01/2017].

PattoSáMotta, Rodrigo(2015), "As políticas universitárias das ditaduras militares do Brasil, da Argentina e do Chile", en Rodrigo Motta (org.), Ditaduras militares. Brasil, Argentina, Chile e Uruguai, Belo Horizonte, Editora UFMG.

Patto Sá Motta, Rodrigo (2014), As universidades e o regime militar, Río de Janeiro, Zahar.

Pérez Lindo, Alberto (1986), Universidad, política y sociedad, Buenos Aires, EUDEBA.

Rodríguez, Laura (2015a), "La Universidad Nacional de La Plata entre 1973 y 1983", en PolHis, año 7, núm. 14, Mar del Plata, <http://historiapolitica. com/2015/06/17/3005/> [Consulta: 13/01/2017].

Rodríguez, Laura (2015b), Universidad, peronismo y dictadura. 1973-1983, Buenos Aires, Prometeo.
Rodríguez, Laura y Germán Soprano (2009a), "Las políticas de acceso a la universidad durante el proceso de reorganización nacional, 1976.1983. El caso de la Universidad Nacional de La Plata", en Revista Questión, vol. 1, núm. 24, primavera(octubre-diciembre), La Plata, UNLP, <http://perio.unlp.edu.ar/ojs/index.php/ question/issue/view/35> [Consulta: 13/01/2017].

Rodríguez, Laura y Germán Soprano (2009b), "La política universitaria de la dictadura militar en la Argentina: proyectos de reestructuración del sistema de educación superior (1976-1983)", en Revista Nuevo Mundo Mundos Nuevos, París, <http://nuevomundo. revues.org/56023> [Consulta: 13/01/2017].

Seia, Guadalupe (2017), "La búsqueda por la institucionalización y 'normalización universitaria' de la última dictadura en Argentina. Ley universitaria, nuevo estatuto y concursos docentes en el caso de la Universidad de Buenos Aires (1980-1983)", en Revista Debate Universitario, vol. 6, núm. 10, julio, Buenos Aires, <http://portalreviscien.uai.edu.ar/ojs/index.php/ debate-universitario/article/view/106> [Consulta: 13/01/2018].

Seia, Guadalupe (2016a), "Militancia, oposición y resistencia estudiantil en la Universidad de Buenos Aires durante la etapa final de la última dictadura (1981-1983)", en Historia, voces y memoria, núm. 10, Buenos Aires, <http://revistascientificas.filo.uba.ar/ index.php/HVM/article/view/3379> [Consulta: 13/01/2018].

Seia, Guadalupe (2016b), "La resistencia contra el arancelamiento en la Universidad de Buenos Aires (UBA) durante la última dictadura (1976-1983)", en VI Fornadas de Estudio y Reflexión sobre Movimiento Estudiantil Argentino y Latinoamericano, Buenos Aires, IIGG-UBA, 1 y 2 de septiembre de 2016.

Seia, Guadalupe (2015), "Una aproximación a la política universitaria entre los años 1974 y 1983: continuidades y rupturas en el caso de la Universidad de Buenos Aires", en XI fornadas de Sociología, Buenos Aires, 
FSOC, Universidad de Buenos Aires.

Seia, Guadalupe (2014), "Rectores de la Universidad de Buenos Aires entre 1974 y 1983: curricula vitae, discursos y comunicados de prensa. Estudio preliminar", en Cuaderno 5 [Programa Historia y
Memoria], Buenos Aires, Universidad de Buenos Aires, <http://www.uba.ar/historia/contenidos. php?id=6\&s=54> [Consulta: 13/01/2017].

Vasilachis De Gialdino, Inés (1992), Métodos cualitativos I. los problemas teóricos-epistemológicos, Buenos Aires, GEAL.

\section{Cómo citar este artículo:}

Seia, Guadalupe (2018), “La aplicación de la política de "re-dimensionamiento" en la Universidad de Buenos Aires durante la última dictadura (1976-1983)", en Revista Iberoamericana de Educación Superior (RIES), México, UNAM-IISUE/Universia, vol. IX, núm. 25, pp. 96-116, http://dx.doi.org/10.22201/iisue.20072872e.2019.25.344[co nsulta: fecha de última consulta]. 